\title{
‘Preoperative imaging should be performed for all cases of acquired nasolacrimal duct obstruction'-No
}

Eye (2017) 31, 349-350; doi:10.1038/eye.2016.236; published online 4 November 2016

The premise of medicine is, in part, the art of navigating risk. The motion for universal preoperative lacrimal imaging strives for the unobtainable—namely, certainty.

When surveyed, $<5 \%$ of responding US members of the American Society of Ophthalmic Plastic and Reconstructive Surgeons used preoperative imaging for patients with presumed nasolacrimal duct obstruction (NLDO). ${ }^{1}$ Given the aforementioned advantages suggested by Freitag et al why should this be?

There are many powerful arguments against universal preoperative imaging, and these are considered as we argue for the judicious use of radiological investigations to increase their positive predictive value.

First, imaging remains an imperfect test: Many intrinsic tumours of the lacrimal outflow tract may not be apparent on dacryocystography (DCG) or CT scan, and are found only incidentally during surgery., ${ }^{2,3}$ While magnetic resonance imaging is valuable for soft tissue characteristics, CT is best suited for detecting bone erosion and newer techniques-such as the reformatting of ultra-thin CT slices-provide greater anatomic detail and have improved diagnostic accuracy. ${ }^{4}$ All imaging has limitations, as primarily axial imaging (as with $\mathrm{CT}$ ) may lose some detail during sagittal or coronal reformatting of an irregular nasolacrimal duct. Likewise, having bone details with CT might be of little practical advantage for earlier diagnosis of disease, as bone erosion will be associated with clinically-advanced disease- - the very opposite of the mantra for universal diagnostic imaging.

Secondly, the positive predictive value (PPV), any test is directly related to the prevalence of disease. Although considerably rarer in our experience, neoplasia as the cause of lacrimal outflow obstruction has been reported in up to $1.4 \%$ of routine biopsies during dacryocystorhinostomies (DCRs), ${ }^{5}$ such tumours are, however, generally evident on clinical history and examination, and high-resolution CT imaging should be reserved for such patients. Thus, any history of cancer will increase the PPV and, if supported by clinical signs, might prompt further imaging. Likewise, nasolacrimal duct stenosis is infrequent in those under 50 years of age, and secondary causes should be considered in such patients. ${ }^{6}$ Men have a higher risk of a neoplastic NLDO, ${ }^{5}$ but a history of epistaxis, punctal bleeding, or pain, are typically unrelated to malignancy. ${ }^{3}$

In practical terms, almost all 'filling-defects' on lacrimal outflow tract imaging are either inspissated debris ('stones'), contrast artefacts due to air bubbles or mucosal folds, or benign papillomas.

As with the vast majority of clinicians in the Nagi and Meyer survey, ${ }^{1}$ we regard outpatient tests to be sufficient for diagnosis in almost all cases. Imaging, with its limitations, should be reserved for only a few select cases. Some authors advocate imaging for bilateral disease, where the odds ratio for a secondary cause has been estimated as $2.59,{ }^{6}$ but-as most secondary disease is non-neoplastic - we do not accept this view unless there is additional supportive evidence, such as chronic nasal disease. In contrast, a medial canthal mass extending above the canthal ligament is suggestive of tumour, ${ }^{7}$ with a sensitivity of $77 \%$ and specificity of $71 \%{ }^{8}$ Likewise, as compared with muco-pyoceles, malignant tumours are usually uninflammed ${ }^{9}$ and tend to be firm, incompressible and nontender, ${ }^{3}$ tumour-related skin ulceration or telangiectasia may occur, ${ }^{10}$ and regional lymphadenopathy is a late sign. 
Thirdly, radiation exposure remains a concern: While helical 3D-CT with reconstruction is advocated by Freitag et $a l^{11}$ there is a significant exposure to ionizing radiation, and this creates a major cumulative risk for secondary malignancy if applied to all patients with NLDO.

The fourth consideration is cost. In our taxpayerfunded healthcare system, an orbital CT costs about $£ 160$ (US\$233), this being more than $10 \%$ of the reimbursement rate for DCR in the UK National Health service: $£ 1,400$ in 2013 or about $\$ 2,037 .{ }^{12}$ Using the neoplastic incidence of $1.4 \%$ reported in Bewes' series, ${ }^{5}$ the number needed to scan is around 70 (98.6/1.4) perhaps a poor use of medical resources.

So are there alternatives to improve outcomes without the need for universal imaging? Biopsy of the lacrimal sac might provide a safety net to ensure malignancy is not missed, and-unlike imaging-the sensitivity, specificity, and predictive value are, by definition, high. Anderson et $a l^{2}$ reported neoplastic disease in $4.5 \%$ of 377 DCR samples, with a half being unsuspected prior to surgery and half being malignant. In our (GER) experience of over 6000 open lacrimal procedures, biopsy has been restricted to any abnormal tissues encountered at surgery; with this policy, there have been only two patients with late occurrence of lacrimal sac lymphoma-one at 8 years and one at 13 years after the primary surgery. All lacrimal sac malignancies were suspected and investigated prior to lacrimal surgery, and the only clinically-unsuspected neoplasia were transitional cell papillomas. Lacrimal sac biopsy is rarely undertaken during DCR in the UK, this possibly being even more so with endoscopic approaches. In contrast, random biopsy is still widely practiced in the US and perhaps the UK experience might provide practical reassurance on this matter?

In practical terms, lacrimal imaging is useful only for major craniofacial anomalies (for example, where there is choanal atresia and one cannot determine whether an airspace is available to create an anastomosis), for occasional redo surgery where the clinical signs do not quite tie-in with a definite scenario, or where there is a tumour (where CT-DCG is most useful). Imaging for functional block is comforting, but not essential by any means, as it does not alter the management-namely dacryocystorhinostomy.

\section{Conflict of interest}

The authors declare no conflicts of interest.

\section{References}

1 Nagi KS, Meyer DR. Utilization patterns for diagnostic imaging in the evaluation of epiphora due to lacrimal obstruction: a national survey. Ophthal Plast Reconstr Surg 2010; 26(3): 168-171.

2 Anderson NG, Wojno TH, Grossniklaus HE. Clinicopathologic findings from lacrimal sac biopsy specimens obtained during dacryocystorhinostomy. Ophthal Plast Reconstr Surg 2003; 19(3): 173-176.

3 Parmar DN, Rose GE. Management of lacrimal sac tumours. Eye 2003; 17: 599-606.

4 Dutton JJ, White JJ. Imaging and clinical evaluation of the lacrimal drainage system. In: Cohen AJ, Mercandetti M, Brazzo BG (eds). The Lacrimal System-Diagnosis, Management and Surgery. Springer Verlag: New York, NY, USA, 2006, pp 74-95.

5 Bewes T, Sacks R, Sacks PL, Chin D, Mrad N, Wilcsek G et al. Incidence of neoplasia in patients with unilateral epiphora. J Laryngol Otol 2015; 129(Suppl 3): S53-S57.

6 Sobel RK, Carter KD, Allen RC. Bilateral lacrimal drainage obstruction and its association with secondary causes. Ophthal Plast Reconstr Surg 2014; 30(2): 152-156.

7 Ryan SJ, Font RL. Primary epithelial neoplasms of the lacrimal sac. Am J Ophthalmol 1973; 76: 73-88.

8 Gupta T, Rose GE, Thaung C, Collin JRO, Uddin JM, Daniel $\mathrm{C}$ et al. Swelling above the medial canthal tendon predictor of sinister pathology. 2013 BOPSS meeting, Bristol.

9 Altan-Yaycioglu R, Bolat F, Akova YA. Basisquamous carcinoma of the lacrimal sac: a case report. Orbit 2007; 26(4): 267-269.

10 Flanagan JC, Stokes DP. Lacrimal sac tumours. Ophthalmology 1978; 85: 1282-1287.

11 Freitag SK, Woog JJ, Kousoubris PD, Curtin HD. Helical computed tomographic dacryocystography with threedimensional reconstruction: a new view of the lacrimal drainage system. Ophthal Plast Reconstr Surg 2002; 18(2): 121-132.

12 Monitor \& NHS England: Statutory guidance. National tariff payment system 2014/15 www.gov.uk/government/ publications / national-tariff-payment-system-2014-to-2015. (accessed 29 March 2016).

$$
\text { JCP Roos }{ }^{1}, \text { DG Ezra }{ }^{2} \text { and GE Rose }{ }^{2}
$$

${ }^{1}$ Department of Ophthalmology, Norfolk and Norwich University Hospital, Norwich, UK

${ }^{2}$ Adnexal Service, Moorfields Eye Hospital NHS Foundation Trust, London, UK

Correspondence: JCP Roos, Department of Ophthalmology, Norfolk \& Norwich University Hospital, Norwich NR4 7UY, UK Tel: +44016032 86286; E-mail: drjonathanroos@gmail.com 